\title{
A expressão da criatividade na aprendizagem da leitura e da escrita: um estudo de caso
}

Luciana Soares Muniz'

Albertina Mitjáns Martínez"

\section{Resumo}

0 presente artigo tem por objetivo destacar as formas em que a criatividade se expressa na aprendizagem da leitura e da escrita da criança. Assume-se como referencial teórico a concepção de aprendizagem criativa desenvolvida por Mitjáns Martínez. Segundo essa concepção, os processos criativos emergem nos contextos de ação do sujeito, mediante recursos subjetivos constituídos historicamente e que se organizam no momento da ação concreta. A expressão desse tipo de aprendizagem tem se configurado pela personalização da informação, confrontação com o dado e pela geração, produção de ideias novas que vão além do que está posto. Adota-se como eixo norteador a pesquisa qualitativa, apoiada nos princípios da epistemologia qualitativa desenvolvida por González Rey, com opção pelo estudo de caso, utilizando instrumentos abertos e semiabertos, tais como: dinâmicas conversacionais, observações, entrevistas como processo e diário de ideias. A investigação foi desenvolvida em uma escola da rede pública, com alunos dos primeiros e segundos anos do ensino fundamental, na qual acompanhamos os aprendizes por dois anos consecutivos. Como conclusão, considera-se que a expressão da criatividade na aprendizagem da leitura e da escrita foi significativamente apresentada pelas características destacadas por Mitjáns Martínez, bem como pela relação lúdica da criança com sua aprendizagem.

\section{Palavras-chave}

Aprendizagem - Criatividade - Leitura - Escrita.

I- Universidade Federal de Uberlândia, Uberlândia, MG, Brasil.

Contato: lucianasoares.muniz@gmail.com II- Universidade de Brasília, Brasília, DF, Brasil.

Contato: amitjans49@gmail.com 


\title{
The expression of creativity in learning how to read and write: a case study
}

Luciana Soares Muniz'

Albertina Mitjáns Martínez"

\begin{abstract}
This paper has the purpose of highlighting the ways through which creativity is expressed in the child's learning of how to read and write. The theoretical assumption taken is the concept of creative learning developed by Mitjáns Martinez. According to such conception, creative processes emerge in the context of the individual's action, through subjective resources that are historically constructed and are organized in the moment of concrete action. The expression of this type of learning has been configured by the personalization of information, confrontation with data, and by the generation and production of new ideas that go beyond what is taken for granted. The guiding axis adopted is qualitative research, supported by the principles of the qualitative epistemology developed by González Rey, with the option of conducting a case study utilizing open and semi-open tools, such as: conversational dynamics, observations, interviews as a process and a diary of ideas. The investigation took place in a public school, among 1st and 2nd graders, in which we monitored the learners for two years in a row. As a conclusion, we consider that the expression of creativity in learning how to read and write was significantly presented by the characteristics emphasized by the author mentioned above, as well as by the playful relationship of the child with his/her learning.
\end{abstract}

\section{Keywords}

Learning - Creativity - Reading - Writing.

I- Universidade Federal de Uberlândia, Uberlândia, MG, Brasil.

Contact: lucianasoares.muniz@gmail.com II- Universidade de Brasília, Brasília, DF, Brasil.

Contact: amitjans49@gmail.com 


\section{Introdução}

0 foco principal deste artigo consiste em apresentar formas em que a criatividade se expressa na aprendizagem da leitura e da escrita da criança, tendo em vista o contexto escolar. 0 presente tema insere-se nas amplas discussões que envolvem as políticas públicas educacionais, em especial o programa Pacto Nacional pela Alfabetização na Idade Certa, que visa a contribuir para a alfabetização de todas as crianças até, no máximo, os oito anos de idade. Nessa perspectiva, estar alfabetizado significa, segundo documento oficial, “[...] ser capaz de interagir por meio de textos escritos em diferentes situações; significa ler e produzir textos para atender a diferentes propósitos" (BRASIL, 2012, p. 17).

Esta concepção de alfabetização possibilita-nos refletir acerca da abrangência e complexidade que envolve a condição de estar alfabetizado e o percurso para que esse processo se realize. Do nosso ponto de vista, tal aprendizagem necessita envolver processos de autoria e de utilização autônoma do saber. Tal compreensão apoia-se no que salienta Freire (2011, p. 19), para quem a alfabetização “[...] não se esgota na decodificação pura da palavra escrita ou da linguagem escrita, mas [...] se antecipa e se alonga na inteligência do mundo".

Pelas múltiplas considerações a respeito dos termos alfabetizar, processo voltado aos aspectos mais tecnológicos da escrita, e letramento, como o uso social da leitura e da escrita, optamos pela utilização do termo aprendizagem da leitura e da escrita, na tentativa de romper com possíveis dicotomias entre a aquisição de um código, a utilização do mesmo em contextos sociais e os processos subjetivos envolvidos. No âmbito da perspectiva histórico-cultural assumida neste trabalho, consideramos as múltiplas nuances que envolvem esse aprender. Concordamos com Freire (2011), Leite (2011) e Smolka (2008), para os quais esse processo é permeado por aspectos culturais, sociais, afetivos e cognitivos.
Ainda assim, a criatividade na aprendizagem da leitura e da escrita não tem sido tema de estudo no campo científico, demandando investimentos de pesquisas nessa área (MUNIZ; MITJÁNS MARTÍNEZ, 2013). A aprendizagem criativa da leitura e da escrita implica uma forma relacional e pessoal de interação da criança com o objeto de conhecimento, em meio a processos de autoria, de dúvidas, de confrontos, de curiosidades, de encontro consigo mesma, tornando a escrita e a leitura processo próprio de se relacionar com o mundo com ênfase na transcendência do que está posto. É um tipo de aprendizagem desejável para que a leitura e a escrita tornem-se processos de aprendizagem e desenvolvimento.

Organizamos o presente trabalho em duas partes. $\mathrm{Na}$ primeira, conceitualizamos a aprendizagem criativa e, em um segundo momento, apresentamos um estudo de caso, na tentativa de evidenciar como a mesma se expressa na aprendizagem da leitura e da escrita, aprendizagem base para todo o decorrer da vida escolar do aprendiz.

\section{Aprendizagem criativa}

No contexto escolar, o aprendiz está imerso em uma gama de conteúdos, informações e conhecimentos que fazem parte do currículo escolar. A relação do aprendiz com tais processos é singular e revela diferenças importantes, permitindo-nos caracterizar tipos de aprendizagem também distintos. Reiteramos González Rey (2008, 2011c), segundo o qual a aprendizagem escolar não pode ser representada apenas pela dimensão cognitivo-reprodutiva, mas como um processo subjetivo evidenciado pela produção simbólico-emocional, em que o próprio aprendiz se envolve na sua condição ativa, intencional, que implica um posicionamento próprio e singular no processo de aprender. Essa possibilidade de atuação ativa refere-se à consolidação de espaços próprios, em que as produções subjetivas dinamizam o caráter confrontador do sujeito diante de suas experiências (GONZÁLEZ REY, 2003, 2011a). 
Como um processo subjetivo, enfatizamos as formas complexas de aprendizagem escolar, as quais guardam características relevantes para o desenvolvimento do aprendiz. Essas têm sido denominadas como aprendizagem criativa e aprendizagem compreensiva (MITJÁNS MARTÍNEZ, 2012b; GONZÁLEZ REY, 2012). Na aprendizagem compreensiva, o sujeito atua de forma intencional para compreender o objeto de conhecimento, num esforço que demanda a atuação de um sujeito ativo, engajado e envolvido emocionalmente. No entanto, nessa aprendizagem, todo o esforço está direcionado à compreensão, à volta ao dado.

A aprendizagem criativa consiste em uma categoria em desenvolvimento que abre possibilidades para pensar processos de aprendizagem complexos, nos quais a produção de ideias novas, que vão além do dado, resulta essencial (MITJÁNS MARTÍNEZ, 2012a, 2012b). Vale marcar que estudos nessa direção, dentro de uma perspectiva histórico-cultural, têm sido delineados especialmente por Mitjáns Martínez (2008, 2009a, 2009b, 2012a, 2012b), autora que inicialmente definiu a aprendizagem criativa como:

[...] uma forma de aprender caracterizada por estratégias e processos específicos, em que a novidade e a pertinência são indicadores essenciais. (MITJÁNS MARTÍNEZ, 2008, p. 86)

Com as pesquisas realizadas e sua aproximação à teoria da subjetividade, bem como munida de sua concepção de criatividade, Mitjáns Martínez (1997, 2000, 2004, 2008, 2009b) avança na sua concepção de aprendizagem criativa compreendendo-a como processo da subjetividade. Essa definição sustenta-se na compreensão da subjetividade na sua dupla condição: social e individual. Sendo assim, não estamos diante de um processo intrapsíquico, mas que emerge na ação do sujeito em contexto, numa relação que não admite polaridades, configurando o caráter gerador da psique (GONZÁLEZ REY, 2011a).
Para Mitjáns Martínez (2012a), a criatividade é uma emergência e não algo que carregamos e que se evidencia nas distintas ações e contextos que experienciamos. Como uma emergência, a criatividade está associada à ação profundamente implicada do sujeito, momento em que há expressão de recursos subjetivos que se constituem ao longo da vida do aprendiz, em condições e contextos de ação subjetivados pela pessoa nos distintos sistemas sóciorelacionais, bem como mediante a produção de sentidos subjetivos que se constituem no devir da ação (MITJÁNS MARTÍNEZ, 2012b).

Como uma aprendizagem complexa, Mitjáns Martínez (2012a, 2012b) tem se dedicado a compreender os elementos que constituem e caracterizam a aprendizagem criativa. Sendo assim, mediante construções teóricas e a partir de pesquisas realizadas com alunos criativos do ensino médio e ensino superior, a referida autora tem caracterizado a expressão da criatividade na aprendizagem a partir da configuração de, pelo menos, três elementos: 1) a personalização da informação; 2) a confrontação com o dado; e 3) a produção, geração de ideias próprias e novas que transcendem o dado.

Tais características demonstram que a relação do aprendiz com a informação ou mesmo com o conhecimento não se estabelece de forma passiva; ao contrário, assume uma orientação ativo-transformadora de implicação "[...] no processo de aprendizagem, convertendo-o em uma via para o desenvolvimento de todas as suas potencialidades" (GONZÁLEZ REY; MITJÁNS MARTÍNEZ, 1989, p. 104). Esta forma de aprender caracteriza-se como uma aprendizagem complexa. 0 sistema educativo histórico que vivenciamos, em que a ênfase está na homogeneização e na reprodução-assimilação, difıculta e muitas vezes inviabiliza a emergência de processos criativos na aprendizagem (MITJÁNS MARTÍNEZ; GONZÁLEZ REY, 2012; MITJÁNS MARTÍNEZ, 2012a).

0 conceito personalização da informação foi elaborado por González Rey e Mitjáns Martínez (1989), os quais precisamente 
contribuíram para pensarmos uma nova e diferenciada forma de relação do homem com a variedade de informações a que é submetido e se submete em seu cotidiano. Tais autores reforçam a ideia de que nem toda informação formará parte da própria constituição subjetiva da pessoa, ressaltando que há informações que ganham relevância e se expressam em ações do sujeito, as quais estão associadas com suas motivações, perfazendo um processo que se efetiva pelo caráter ativo, na individualização que o sujeito realiza.

Esse conceito assume relevância para caracterizar a aprendizagem criativa, uma vez que, na medida em que estamos ativamente aprendendo algo, na busca incessante de transformar, formar uma representação própria, na relação com nossos conhecimentos prévios, somos capazes de atuar com esse aprendizado em distintas situações que experienciamos. Assim, esse aprender passa a se constituir em nós como um recurso subjetivo, que permite transcender o que foi dado (GONZÁLEZ REY; MITJÁNS MARTÍNEZ, 1989).

Com a personalização, não apenas recebemos a informação de forma passiva, para reproduzi-la ou compreendê-la, mas, em um processo de engajamento como sujeito, a informação é transformada em algo que está para além dela, processo que nem sempre é consciente para o aprendiz. Diante do que aprende, o aluno é capaz de questionar, de duvidar, de identificar lacunas e contradições, o que só é possível mediante um grau elevado de envolvimento, de entrega ao que se propõe a novas descobertas, num movimento de embates constantes, permitindo-lhe uma aproximação pessoal e própria do que está aprendendo (MITJÁNS MARTÍNEZ, 2012b).

A confrontação com o dado está para um saber não cristalizado, mas que se movimenta e se transforma na medida em que o sujeito se coloca de forma reflexiva frente ao que está aprendendo. Aqui, não há simplesmente uma internalização ou mesmo uma apropriação de algo que é externo e que está apenas pronto para ser consumido. Há, sim, algo que, para que possa ser aprendido, requer confrontos que atualizam os saberes de que já dispomos e os colocam também em dúvidas, a fim de colocar à prova o conhecimento, desnaturalizando o olhar para aquilo que forma parte do aprendizado. $\mathrm{Na}$ escola, confrontar-se com os conteúdos é quase uma exceção, dificultando as possibilidades de emergência da criatividade, na geração de ideias próprias, que de fato terão impactos na vida do aprendiz e não simplesmente servem para obter uma nota.

Todo o processo de personalizar a informação, de confrontar-se com o que é dado, em um processo de singularização do aprender, tem em si o que essencialmente caracteriza a aprendizagem criativa: a geração de ideias próprias que transcendem o que se estuda. Produzir, gerar ideia própria e nova configura-se, na aprendizagem criativa, na forma como o sujeito não se limita a entender algo, mas passa pela compreensão e é capaz de transcender o que está posto.

$\mathrm{Na}$ aprendizagem criativa, a complexidade funcional do sujeito no contexto da ação revela as suas especificidades e o novo assume uma qualidade de transcendência, podendo ter impactos sobre o desenvolvimento da subjetividade. Nesse tipo de aprendizagem, o produto criativo pode estar expresso na personalização, pelo aprendiz, das informações que transcendem o que está posto, na autoria do pensamento e das produções que individualizam o processo de aprender, nas perguntas interessantes e originais que elabora frente à confrontação com o dado, dentre outras possibilidades. Importa ressaltar que o produto criativo deve, de alguma forma, transcender o dado (MITJÁNS MARTÍNEZ, 2008; AMARAL, 2011).

Vale ressaltar que a personalização da informação, a confrontação com o dado e a geração de ideias novas podem estar presentes em outro tipo de aprendizagem, por exemplo, na compreensiva. No entanto, cumprem a função de se voltar ao dado, de apenas compreender o que está posto, diferenciando-se da aprendizagem criativa na qual o sujeito 
personaliza a informação e gera ideias que transcendem o que está posto.

Frente ao exposto, aprender criativamente, pela complexidade que envolve esta ação, favorece, dentre outros aspectos, a estabilidade do aprendido, não constituindo um aprendizado momentâneo, mas que se efetiva nas possibilidades de gerar algo próprio, utilizando esse novo saber em diferentes situações vividas pelo aprendiz, bem como pode possibilitar o bem estar emocional do aluno e sua realização pessoal (MITJÁNS MARTÍNEZ, 2012b).

Portanto, pretendemos, nos próximos tópicos, aventurar-nos para compreender como a criatividade se expressa na aprendizagem da leitura e da escrita da criança. Teremos como referência as características já elaboradas por Mitjáns Martínez, com alunos do ensino médio e ensino superior, buscando tecer as possíveis relações e especificidades.

\section{Metodologia}

Para a investigação aqui delineada, adotamos como eixo norteador a pesquisa qualitativa, apoiada nos princípios da epistemologia qualitativa desenvolvida por González Rey (1997, 2005, 2009, 2011b), orientada à pesquisa da subjetividade, tendo em vista uma perspectiva complexa e histórico-cultural. Nesse viés, optamos pelo estudo de caso, utilizando instrumentos abertos e semiabertos, tais como:

- Dinâmicas conversacionais - expressão livre dos sujeitos a respeito de temas do seu interesse;

- Entrevista como processo - a partir de algumas questões norteadoras com os sujeitos, dialogar acerca das ações empreendidas para aprender;

- Observação: realizada em sala de aula e em outros momentos do cotidiano escolar;

- Diário de ideias - caderno em branco entregue para a criança no início da pesquisa, o qual a acompanhará ao longo de todo o percurso da pesquisa, visando a privilegiar um espaço de produção espontânea da criança.

0 caminho de análise das informações derivou-se de um processo construtivo-interpretativo, mediante a elaboração de indicadores que foram construídos a partir de nossa análise das informações, na confluência dos diversos instrumentos (GONZÁLEZ REY, 2005). Vale ressaltar aqui que os participantes da pesquisa foram escolhidos a partir de nossas observações em sala de aula e dinâmicas conversacionais com alunos, professoras e familiares. Dentre os elementos relevantes para a escolha e que estiveram atrelados à relação da criança com a leitura e a escrita, podemos citar: interesse, envolvimento, tempo dedicado às atividades, tipos de perguntas realizadas, bem como a forma como a leitura e a escrita estavam presentes para além do contexto escolar.

\section{A expressão da criatividade na aprendizagem da leitura e da escrita de Murilo}

No decorrer da aprendizagem da leitura e da escrita de Murilo, identificamos características que constituíram esse processo como eminentemente criativo. Interpretamos que os elementos que compõem a sua aprendizagem não se deram de forma isolada, mas como processo articulado, em que se perpassavam e favoreciam a complexidade constitutiva da expressão da criatividade na aprendizagem da leitura e da escrita.

Mediante a documentação escolar de Murilo, constatamos que ele iniciou sua vida escolar com quatro anos de idade, também em uma escola da rede municipal de ensino, local em que estava no primeiro período da educação infantil. Aos cinco anos, ingressou na escola em que foi desenvolvida a pesquisa, matriculado no segundo período e, em 2013, cursava o segundo ano do ensino fundamental, 
completando oito anos de idade. A referida escola, na qual acompanhamos Murilo por dois anos consecutivos, é pública e atende crianças de um bairro da periferia da cidade, abrangendo as turmas da educação infantil ao $5^{\circ}$ ano do ensino fundamental.

Construímos informações que evidenciaram, na aprendizagem de Murilo, os três aspectos destacados por Mitjáns Martínez (2012a) na caracterização da aprendizagem criativa: a personalização da informação, a confrontação com o dado e a produção e geração de ideias próprias que transcendem ou vão além do dado, bem como a relação lúdica que incluímos em nossa construção teórica. As ações de Murilo no campo da aprendizagem da leitura e da escrita se expressaram no contexto escolar e se organizaram em meio aos sistemas relacionais, com ênfase na relação com as professoras e com os colegas da turma, pelos tipos de atividade-comunicação, pela dinâmica e organização do espaço-tempo de aprender e se evidenciaram a partir de sua expressão espontânea na relação com a leitura e a escrita.

\section{Personalização da informação}

\section{a) Personalização das explicações e do modo de ensinar da professora}

É preciso destacar a forma atenta como Murilo observava as ações da professora e, principalmente, as suas explicações durante a aula. Construímos a hipótese de que essa observação constituiu uma forma pela qual o aprendiz conseguiu encontrar possibilidades de se expressar reflexivamente perante as solicitações da docente. Em vários momentos de nossas observações, identificamos como Murilo personalizava as solicitações da professora, o que pode ser exemplificado a partir da fala: "A tia pediu. Mas ela pediu pra desenhar e eu quis escrever, pra ler depois." (Entrevista como processo com Murilo - $2^{\circ}$ ano). Tal exemplo expressa a forma ativa e intencional com que Murilo experienciava sua aprendizagem com desdobramentos em ações cotidianas.

Murilo também personalizava a própria metodologia da professora, pelo seu alto grau de envolvimento com o trabalho pedagógico, capaz de configurar formas de aprender que lhe eram próprias. Ele demonstrava um conhecimento profundo da forma de trabalho da docente, o que pode ser exemplificado, aqui, na escrita da palavra LILA para o Diário de ideias. 0 menino disse:

Porque Lila é I, aí tem o mesmo som LILA, I, aí o que eu vi na BOLA, BO - LA, aí eu vi que é o LA. A tia fala que é o som da letra que é pra olhar, mas dá pra saber com outra palavra que a gente já viu ou sabe falar. (Diário de ideias $-1^{\circ}$ ano)

\section{b) Personalização das atividades propostas}

Murilo gerava uma aproximação particular e próxima com as atividades a serem realizadas. Podemos exemplificar tal construção a partir de um momento de produção espontânea de texto, em que, ao se ver diante de uma folha em branco e na busca por uma escrita própria, procurou algo para escrever. Ao ver a colega Amanda, ele lembrou-se do dia em que ela rasgou um desenho que tinha feito de um bombeiro. Quando viu a menina arrancar a cabeça do bombeiro, disse: "Nossa! Ficou agora um bombeiro sem cabeça, é a lenda do bombeiro sem cabeça! Eu ainda não escrevi isso. Eu só falei (risos)” (Observação $2^{\circ}$ ano).

Tal fato remeteu-lhe à escrita da lenda na sua produção de texto. 0 que nos mobilizou a olhar para esse exemplo foi a maneira como Murilo transformava a atividade em algo pessoal, ou seja, não se limitava a copiar do colega, ou mesmo a perguntar à professora o que era para escrever. 0 menino tornava a atividade algo próprio e particular com implicações para ações que postergavam o ato de escrever. Ele passou a contar para os colegas a lenda do 
bombeiro, estabelecendo vínculos afetivos. Esse exemplo revelou não só o envolvimento do aprendiz, mas a busca pela contextualização na sua concretização e nos instigou a pensar que:

0 sujeito só vai desenvolver-se na tensão de sua produção singular ante a possibilidade de alimentar com sua experiência o que aprende e de alimentar o seu mundo com aquilo que aprende. (GONZÁLEZ REY, 2008, p. 32).

\section{c) Personalização do contexto de aprendizagem}

A personalização do contexto de aprendizagem favoreceu uma relação de criação, em que tornava esse ambiente próprio e pessoal. Murilo gerava e criava uma forma de registrar o conteúdo escrito em um caderno pessoal, na medida em que atribuía sentido às músicas e às receitas que ali estavam como possibilidades de utilização das mesmas em outros contextos, como em sua casa, bem como pela forma como criava novas palavras a partir das existentes.

Tal fato pode ser ilustrado pelo seu relato:

Sabe por que eu mandei meu primo fazer aquele caderno? Porque aí tem coisas na escola que é bão, aí não tem caderno pra escrever, aí eu mandei ele fazer um. Tem aquelas musiquinhas lá, tem vez que faz biscoito, aí eu escrevo a receita lá. Eu até inventei palavras, tinha lá CORAÇÃo e eu fız CÃO (Dinâmica conversacional com Murilo - $1^{\circ}$ ano).

É neste processo que se pode pensar na sala de aula como espaço-tempo de aprendizagem, na medida em que possa ser explorado na busca pelo novo, pelo inusitado (CHAMBERLAIN, 2005). A forma como Murilo personalizava o contexto de aprendizagem reverberava em ações para seu cotidiano familiar, que lhe permitiam cantar músicas com sua irmã ou mesmo fazer as receitas com sua mãe.

\section{Confrontação com o dado}

a) Confrontação com suas próprias produções

A confrontação com suas atividades foi marcada pela relação positiva de Murilo com os próprios erros, com os quais demonstrava ter uma relação positiva, de forma crítica e também alegre. A forma como ria de seus erros e o modo autônomo de correção chamava a nossa atenção para a confrontação com que se colocava diante das próprias construções no campo da escrita e da leitura. Esse confronto dava-se no devir da realização das atividades e se concretizava na forma dialógica com que realizava cada tarefa: "Eu penso e faço de novo. Eu olho e vejo se tá errado mesmo e apago e faço de novo" (Entrevista como processo com Murilo - $2^{\circ}$ ano).

$\mathrm{Na}$ sua escrita, Murilo conversava baixinho com ele mesmo dizendo: "Não. Não é assim que escreve. É com A". Esta linguagem para si, como um diálogo, expressou o papel fundamental da comunicação para o pensamento reflexivo. Em outro momento, após escrever, apagar, escrever novamente e observando a própria escrita da palavra PASSARINHO, disse para si mesmo: "Pensa que me engana hein letrinha?" (Dinâmica conversacional com Murilo - $1^{\circ}$ ano). Essa fala de Murilo com sua própria escrita indica o papel organizador da fala egocêntrica no processo de aprendizagem da leitura e da escrita, como expresso por Cavaton; Barbato (2011).

b) Confrontação de ideias

Nos processos de correção da atividade de escrita espontânea, observamos que a professora chamava individualmente os alunos em sua mesa para fazer a correção. Em um episódio de observação, presenciamos a correção da palavra PAPAI, que estava escrita por Murilo da seguinte forma: PAPAE. A professora estabeleceu uma forma dialógica com ele, pedindo para que lesse a palavra e 
indagava-o com algumas perguntas: "Murilo, você acha que tem alguma letra errada?” (Fala da professora Melissa - $1^{\circ}$ ano).

Murilo lia silenciosamente a palavra e não identificava nada de errado. A professora voltava-se para o som das letras e repetia sempre com intensidade o final PAI. Ela escreveu a grafia correta no caderno de Murilo que, ao voltar para o seu lugar, disse: "Eu não vou apaga não. É PAPAE mesmo” (Observação - $1^{\circ}$ ano). No entanto, Murilo colocou-se a pensar a respeito do que a professora lhe disse e buscou em seu caderno uma atividade que tinha a palavra PAPAI. Após encontrá-la, leu novamente a palavra escrita e disse: "É com I mesmo! Mas a gente fala PAPAE” (Observação - $1^{\circ}$ ano).

Murilo também buscava conhecer a estrutura dos livros, suas partes e a forma como são escritos. Ele sabia as informações que deveriam conter na capa e no livro como um todo. No entanto, o menino questionava alguns padrões:

Eu não sei pra que aquela outra capa do livro. Ela repete tudo da capa. Se já leu uma vez, pra que fica repetindo. Só gasta papel. Eu não faço essa outra capa no meu livro não. (Dinâmica conversacional)

Esse questionamento incluía um conhecimento profundo dos livros, que vinha de sua exploração dos materiais escritos e do caráter subversivo e transgressor do sujeito. Em meio às possibilidades de poder mudar o que era instituído, expressava a criação de regras próprias que, posteriormente, no item da relação lúdica do presente trabalho, iremos explorar.

\section{Geração de ideias próprias que vão além do dado}

a) Geração de ideias próprias a partir das próprias produções que vão além do que é solicitado ou mesmo dado

A geração de ideias a partir de suas próprias produções foi, por nós, identificada nos mais variados momentos do cotidiano escolar de Murilo. Tal fato pode ser exemplificado quando fez a leitura de uma história que criou a partir de uma palavra que aprendeu na sala de aula, em um momento de ditado. Quando Murilo perguntou o significado da palavra para a professora, descobriu que jaca era uma fruta e que, na casa da sua avó, tinha um pé de jaca. Tal descoberta o instigou à escrita pessoal de uma história a respeito da fruta em um momento posterior à aula.

Esse movimento de ir além do que a escola solicitava e se aventurar no campo da escrita pessoal foi identificado por nós em vários momentos da pesquisa e revelava a busca de Murilo por novas aprendizagens. Havia uma relação próxima dele com a escrita, que se mostrava na sua preocupação em tornar a escrita viva, uma vez que utilizava o próprio vocabulário para conferir dinamicidade à sua produção, como expresso na forma como se referiu à sua produção sobre a jaca: "Então foi vocês que estavam com fome, né? Eu pus assim, 'né' para ver se as galinhas estavam mesmo ouvindo (risos)" (Diário de ideias $-2^{\circ}$ ano).

Outro exemplo refere-se ao momento em que Murilo, após concluir uma atividade de registro da letra inicial de algumas palavras, voltou-se a olhar para um cartaz, afixado na parede da sala de aula, com a letra da música PIPOCA. Ele fez a leitura do cartaz em tom baixo e, em seguida, disse para um colega:

Sabe aquele cartaz lá. A tia colocou PIP0CA e eu pensei que podia ser MILHO. Sabe por quê? A PIPOCA já é o MILHO que explodiu e na música é tudo PIPOCA. Devia começar com MILHO e só depois PIPOCA (risos). (Observação - $2^{\circ}$ ano)

\section{b) Geração de ideias para além das histórias que} conhece: a criação de livros

A relação que Murilo estabeleceu com os livros foi extremamente particular e revelava a sua admiração por tais materiais. Identificamos a forma como ele observava a professora segurar 
o livro para contar histórias e os momentos em que terminava as atividades de cópia da lousa de forma rápida para poder pegar um livro para ler. Esse fato chamou-nos a atenção por não se tratar de uma prática pedagógica da sala de aula, mas foi criada por Murilo e posteriormente adotada pela professora para toda a turma. Todos esses comportamentos, perpassados pelo pouco contato com livros em casa, foram revelando-nos a curiosidade e o desejo de Murilo pelo objeto do conhecimento.

Murilo era extremamente observador e gostava de ver os detalhes dos livros. Pelo seu gosto por histórias e principalmente pela forma espontânea como as inventava, começa a registrar suas ideias por meio da produção de livros. Em um momento de diálogo ele relatou:

Eu pedi as folhas pra tia Flávia. Ela perguntou que que eu ia faze, se era um desenho, uma história. Eu falei que era um livro. Ela me deu as folhas. Eu colei cada folha, dobrei uma por uma e colei cada uma e fiz o livro. Aí eu coloquei o número de cada página. Aí veio na minha cabeça que eu queria escrever uma história do leão e do gato. Eu nem tenho livro lá na minha casa. Agora eu tenho, to escrevendo um tantão. (Dinâmica conversacional com Murilo - $2^{\circ}$ ano)

Ao longo do segundo ano do ensino fundamental, Murilo produziu mais de dez livros com diferentes títulos e todos se colocando como autor e ilustrador. Chamou nossa atenção a forma interativa que procurava estabelecer com seu leitor, a produção de histórias que não se fixavam no real, o que demonstrava para nós o papel da imaginação na produção e na geração de algo que está para além do contexto real (MITJÁNS MARTÍNEZ, 2012a). As histórias criadas por Murilo estimavam um valor para ele mesmo, uma realização pessoal, num processo de composição, no exercício pleno da imaginação criativa. Nesse sentido, o valor da produção de Murilo não se encontrava apenas na materialização do livro, mas no processo de sua elaboração.

Murilo criou histórias relacionadas a animais e sempre buscava escrever algo que fosse diferente do que habitualmente conhecemos. Para ilustrar, citamos aqui um trecho que inicia uma de suas histórias:

\author{
Vocês acha assim \\ 0 leão vai comer o gato \\ Mais nessa Estoria \\ Os dois é amigo \\ Você já viu um gato \\ Na floresta? Não, né? \\ Si você nunca viu \\ Então você vai ver agora. \\ (Trecho do livro escrito por Murilo - $2^{\circ}$ ano)
}

Interessante perceber a forma como Murilo brincava com suas ideias e procurava transcender o que já conhecia e o que era comum como, por exemplo, o fato de sempre o leão comer o gato por ser mais forte e também de buscar surpreender o leitor colocando o gato em um habitat que não lhe era próprio.

\section{A relação lúdica no processo de aprendizagem criativa da leitura e da escrita}

Em consonância com as características supracitadas, lançamos o olhar para a especificidade e singularidade que envolve a aprendizagem criativa da leitura e da escrita de Murilo e identificamos uma relação lúdica que permeou a forma como se imbuía nas ações de ler e de escrever. Na nossa abertura para compreender como a criatividade se expressava e também se especificava na forma como Murilo aprendia, observamos que as situações concretas em que ele experienciava a leitura e a escrita se caracterizaram por um intenso envolvimento, por uma implicação voluntária e gratuita de se imbuir de maneira 
plena nas atividades, em que a comunicação se expressava das mais diversas formas, bem como observamos o papel da imaginação, do faz de conta e da criação de regras próprias.

Todo esse funcionamento de Murilo moveu-nos a estabelecer intricadas relações com a dimensão lúdica na aprendizagem criativa e, dentre os vários autores que tratam o tema, vamos basear-nos naqueles em que o lúdico não é dado pela especificidade da atividade de jogo em si, mas pela relação que se estabelece com qualquer atividade. Por isso, estamos trazendo, como termos que se inter-relacionam ao lúdico, o jogo, o brinquedo e o brincar (BENJAMIN, 2002; BROUGÈRE, 1998b).

Para nós, Huizinga (1999) define elementos essenciais que caracterizam uma atividade como lúdica: uma atividade voluntária, em que a liberdade constitui fator fundamental; o caráter desinteressado, gratuito que favorece uma evasão da vida real, tendo consciência de estar fazendo de conta; caracteriza-se também pelo isolamento e pela limitação, processando-se em campos delimitados de maneira material ou mesmo imaginária, deliberada ou espontânea; bem como reina uma ordem específica e absoluta. Nesse viés, tal autor possibilita-nos estabelecer relações com a aprendizagem criativa da leitura e da escrita, a qual se realiza, dentre outras, pelas características que configuram uma atividade lúdica.

Um importante elemento do lúdico que se expressou na aprendizagem criativa refere-se às possibilidades que as ações de ler e de escrever têm de distanciar a criança da vida cotidiana, num processo de submersão, capaz de criar um universo diferenciado do que experiencia. Além disso, assim como no jogo, aqui também entendido como lúdico, na escrita e na leitura, a criança está diante de uma atividade constituída socialmente e cria suas próprias regras para realizá-la. Aproximamo-nos cada vez mais da dimensão lúdica na aprendizagem da leitura e da escrita ressaltando aqui a concepção de Brougère (1998a, 1998b, 2002, 2008), para o qual o jogo é visto como espaço social que supõe regras em que a escolha e a decisão constituem partes que iniciam e caminham com o desenvolvimento do jogo:

A regra produz um mundo específico marcado pelo exercício, pelo faz-deconta, pelo imaginário. Sem riscos, portanto, o jogo não é somente um meio de exploração, mas também de invenção. (BROUGĖRE, 1998a, p. 193).

Tal aspecto interessa-nos sobremaneira para explicitar o potencial que as características do lúdico imprimem para o caráter inventivo do aprendiz, que é enriquecido pelas suas experiências da vida cotidiana, sendo por elas orientado (KISHIMOTO, 2011). Estamos de acordo com Vigotski (2009) ao destacar dois elementos das marcas da brincadeira na criação infantil: a primeira relaciona-se ao caráter instantâneo da criação da obra pela criança, ou seja, de realizar de forma intensa e de uma só vez a sua criação; e, em segundo lugar, a ligação com o interesse e a vivência pessoal da criança.

$\mathrm{Na}$ aprendizagem criativa da leitura e da escrita, estão metamorfoseados os processos que envolvem o jogo e o brincar, na singularidade de cada criança, em especial quando criam suas próprias formas de registro, mesmo que mediante regras pré-estabelecidas, e reinventam suas experiências para registrálas. É nessa perspectiva que consideramos que, nas elaborações da escrita, a criança brinca ao registrar algo (COSTA; SILVA; SOUZA, 2013). A aprendizagem da leitura e da escrita está, assim, revestida por funções do brincar que permeiam as descobertas da criança a respeito do sistema alfabético de escrita (BARBATO, 2008).

A partir do exposto e das nossas construções mediante o caso em estudo, elencamos abaixo quatro eixos de análise da relação lúdica como característica da aprendizagem criativa da leitura e da escrita, uma vez que favorece uma relação com o aprender que transcende a experiência em devir. 
a) Relação completa, voluntária, próxima, instantânea e investigativa

Em nossas observações no contexto escolar, foi possível perceber a realização pessoal, voluntária e gratuita de Murilo com suas próprias produções escritas e de leitura, sem exigências externas que tornassem a ação de ler e de escrever uma obrigação. Para Murilo, os momentos de leitura ou de escrita eram deleites, uma entrega à atividade que lhe permitia, em um único momento, trabalhar de forma intensa, séria. Ao mesmo tempo, pelo caráter desafiante de um registro pessoal, ele, de forma instantânea, criava de uma só vez.

Como um artista em sua obra, ou como uma criança quando brinca, a leitura e a escrita na aprendizagem criativa podem constituir-se processos verdadeiramente vivenciados em sua plenitude pelo caráter lúdico. Murilo expressou, em distintos momentos da pesquisa, a forma como brincava com suas ideias: "Sabia que quando eu to escrevendo e até desenhando eu acho que to brincando de palavras, de inventar ideias? [risos]" (Diário de ideias - $2^{\circ}$ ano). Tal fala remete-nos ao que Huizinga (1999, p. 11) defende como uma importante característica do jogo: "[...] atividade temporária, que tem uma finalidade autônoma e se realiza tendo em vista uma satisfação que consiste nessa própria realização."

Murilo envolvia-se totalmente e assim como em uma brincadeira ou jogo, em que a criança vivencia o momento de forma plena, ou seja, não há etapas que postergam a ação, a atividade é iniciada, realizada e concluída de uma só vez:

Eu ia fazendo, aí eu pensava dois minutos, aí eu escrevo de novo. Eu pensava e escrevia. Eu li três vezes depois que eu escrevi. Eu fiz o livro rapidão e nem parei pra nada. (Dinâmica conversacional com Murilo - $2^{\circ}$ ano)

Tal como explicita Vigotski (2009, p. 93), a criança:
[...] cria a obra numa sentada. Sua criação lembra, nesse caso, a brincadeira que surge de uma forte necessidade e permite, quase sempre, uma descarga rápida e completa dos sentimentos que dominam a criança.

\section{b) Relação de comunicação: uma forma investigativa}

Em nossas interações com Murilo, fomos observando a forma como os processos de comunicação formavam parte das ações de ler e escrever. Em muitos momentos, Murilo admirava-se com os livros e fazia o movimento de mostrar ao outro, seja o colega ou mesmo a professora, aquilo que lhe chamava a atenção. Foi como se o estabelecimento da relação com o outro de querer dividir as suas descobertas e o seu encantamento por algo, proporcionasse-lhe bem-estar e entrega à leitura e à escrita.

A comunicação com o outro foi algo presente em sua aprendizagem e expressava o caráter interativo do aprender. Podemos exemplificar esse caráter por meio da atividade com bala, realizada em sala de aula. A professora Melissa, do primeiro ano, solicitou que os alunos chupassem uma bala e tentassem descobrir o seu sabor. Murilo fechou os olhos e sentiu o sabor da bala, porém ele não identificou o sabor. Nesse momento, colocou-se a investigar o papel da bala e a falar cada letra, tentando ler o que estava escrito. Quando ele descobriu que era CARAMELO, imediatamente se virou para o colega do lado e lhe mostrou o papel da bala, indicando ao outro um caminho para aprender.

Ao mesmo tempo, a própria leitura lhe proporcionava uma comunicação com o que via ou mesmo lia. Fato que observamos inúmeras vezes no decorrer da pesquisa, tal como quando leu a história sobre um sapo. Murilo ia conversando com o livro: "Foi você sapo que estava na casa?” (Observação - $1^{\circ}$ ano). Essa comunicação lhe favorecia investigar e até mesmo questionar o próprio enredo da história, como ele disse: "Eu invento história que eu vejo que não tá no livro. Aí eu vejo que pode ser 
diferente, que no livro tá de um jeito, mas vira outra história" (Diário de ideias - $2^{\circ}$ ano).

\section{c) Criação de um cenário imaginário próprio}

A relação lúdica esteve resguardada na forma intensa e despreocupada com que Murilo realizava suas atividades de leitura e escrita. A sala de aula pulsava em agitação dos alunos, um intenso barulho, porém, Murilo não se distraía e não gostava de ser incomodado, principalmente nos momentos de escrita espontânea. Ele não se preocupava com o tempo de término da atividade, mas com a concretização de suas ideias. A conclusão de suas ações no campo da leitura e da escrita estava na completude do que se propunha a realizar e não vinculada a fatores externos:

Quando tem uma tarefa, eu fico pensando o que que eu posso faze. A tia gosta que faz de um jeito e tem vez que eu faço do jeito da tia, mas faço muito mais. Os meninos fazem de qualquer jeito e eu fico um tempão fazendo a tarefa. (Entrevista como processo com Murilo - $2^{\circ}$ ano)

Em muitos momentos de escrita espontânea, conversamos com Murilo a respeito das ideias que registrava e ele era enfático em dizer: "Não é verdade não. Isso é só coisa da minha cabeça. Nem existe” (Observação - $2^{\circ}$ ano). Aqui, estamos diante da forma como Murilo criava possibilidades de escrita que estão para além da realidade por ele experienciada em sala de aula e demonstrava consciência de estar se aventurando em um mundo de faz de conta. A imaginação foi a fonte da ludicidade na aprendizagem da leitura e da escrita e permitiu que Murilo criasse, inventasse. No entanto, é preciso ressaltar que toda a dimensão lúdica em experienciar a aprendizagem da leitura e da escrita não se limitava ao produto escrito ou à verbalização da leitura, mas se processou no devir das ações de Murilo.

Esta relação inteira com a atividade favorecia a Murilo se transportar para um mundo imaginário, que lhe permitia estabelecer relações com experiências ou mesmo se reportar a criações que não se limitavam ao tempo e ao espaço concreto da realidade em si, transcendendo os limites do espaço-tempo das ações de ler e escrever, revelando-nos uma entrega de múltiplas possibilidades de brincar com suas próprias ideias. Murilo criava um cenário lúdico, em que imitava, inventava, organizava o universo adulto da escrita e da leitura e o seu próprio cenário social, aspectos destacados por Benjamin (2002). Há uma relação espontânea com a leitura e a escrita, pautada pela liberdade de expressão, de entrega à experiência de ler e de escrever de forma gratuita e despreocupada.

\section{d) Criação das próprias regras}

Um elemento que nos chamou a atenção foi a criação de regras para a realização de atividades de registro escrito ou de leitura. Murilo criava regras tais como: "Não pode olhar no do colega, é pra faze sozinho." "É só olha as linhas da folha e vai sabe como a história vai termina. Quando eu to escrevendo e vejo que já ta chegando o final da linha eu termino a história. Tem vez que eu escrevo atrás da folha." "Eu não gosto que os menino fica me pedindo material emprestado, bem na hora que eu to pensando o que que eu vou escreve." "Eu invento o que ta aqui na minha cabeça" (Dinâmica conversacional com Murilo $-1^{\circ}$ e $2^{\circ}$ ano).

Murilo estabeleceu regras próprias e também ressaltou aquelas que eram exigidas pela professora. Para ele, as regras precisavam ser cumpridas e ele se lançava nas atividades com a confiança de que estava resguardado pelas mesmas e podia ousar nos seus registros. Murilo atribuía significado ao lápis e ao papel como materiais que possibilitavam a expressão de suas ideias, fantasias e sua imaginação. Os materiais de leitura e de escrita constituíam-se como brinquedos, ou seja, não ficavam vinculados a padrões externos de cópia ou mesmo para reproduzir ideias, mas aguçavam o desejo de aprender na inventividade. 
Portanto, diante da análise construtivo-interpretativa, convalidamos a complexidade que envolve a aprendizagem da leitura e da escrita e, mais especificamente, compreendemos que a criatividade emerge nesse processo por um conjunto de elementos que puderam ser elucidados na singularidade do caso aqui configurado, convalidando a sua não restrição a um ou outro elemento, mas resguardada pela confluência das características que se apresentaram.

\section{Considerações finais}

Dispor de informações a respeito de como a criatividade emerge na aprendizagem da leitura e da escrita contribui imensamente para o enfrentamento dos desafios que assolam o campo da aprendizagem da leitura e da escrita, uma vez que ações pedagógicas intencionais e personalizadas podem favorecer a expressão do sujeito da aprendizagem em prol do desenvolvimento integral do aprendiz. Estamos ressaltando a sua importância para que se possa ter uma relação próxima, pessoal e de autoria com os processos de leitura e de escrita e acreditamos que a aprendizagem criativa está em consonância com a proposta das políticas públicas no campo da alfabetização.

Mediante nossas análises do caso apresentado, foi possível identificar e convalidar a emergência dos três elementos já expostos por Mitjáns Martínez, a partir de seus estudos de alunos do ensino médio e ensino superior. Com suas especificidades, encontramos em Murilo a forma personalizada com que se relacionava com as informações e a própria metodologia da professora, bem como com o contexto de aprendizagem da sala de aula, na forma como confrontava o seu próprio conhecimento com algo que estava aprendendo, e também se confrontava com sua própria produção, na geração e produção de ideias que culminaram em novas aprendizagens e na elaboração de livros.

Como elemento novo ao campo teórico da aprendizagem criativa, ressaltamos a dimensão lúdica que perpassa essa forma de aprender e lhe confere uma relação pessoal e espontânea, de investigação, de voluntariedade e um caráter instantâneo. Dentro dela, observamos processos de comunicação, bem como ressaltamos o papel da criação de um cenário imaginário, tendo em vista o faz de conta, bem como da criação de regras nas ações que envolviam leitura e escrita.

Portanto, ressaltamos aqui o valor da aprendizagem criativa para uma relação com a leitura e a escrita que possibilita a transcendência do que está dado, com ênfase no caráter gerador do humano. Constitui, assim, importante desafio de estudos futuros que busquem explorar as produções subjetivas da criança no processo de aprendizagem criativa da leitura e da escrita, tema que estamos em fase de investigação e publicação.

\section{Referências}

AMARAL, Ana Luiza Snoeck Neiva do. A constituição da aprendizagem criativa no processo de desenvolvimento da subjetividade. 2011. 243 f. Tese (Doutorado em Educação) - Universidade de Brasília, Brasília, DF, 2011.

BARBATO, Silviane Bonaccorsi. Integração de crianças de 6 anos ao ensino fundamental de nove anos. São Paulo: Parábola, 2008.

BENJAMIN, Walter. Reflexões sobre a criança, o brinquedo e a educação. São Paulo: 34, 2002.

BRASIL. Pacto nacional pela alfabetização na idade certa. 2012. Disponível em: <http://pacto.mec.gov.br/images/pdf/pacto_ livreto.pdf >. Acesso em: 07 jan. 2014.

BROUGÈRE, Gilles. A criança e a cultura lúdica. Revista da Faculdade de Educação, São Paulo, v. 24, n. 2, p. 103-116, jul./ dez. 1998b. 
BROUGÈRE, Gilles. Brinquedo e cultura. São Paulo: Cortez, 2008.

BROUGĖRE, Gilles. Jogo e educação. Porto Alegre: Artes Médicas, 1998a.

BROUGÈRE, Gilles. Lúdico e educação: novas perspectivas. Linhas Críticas, Brasilia, DF, v. 8, n. 14, p. 5-20, jan.jun. 2002.

CAVATON, Maria Fernanda Farah; BARBATO, Silviane. A fala egocêntrica da criança de seis anos na construção coletiva da escrita. Acolhendo a Alfabetização nos Países de Língua Portuguesa, v. 6, n. 11, p. 78-102, set. 2011. Disponível em: <http://www. acoalfaplp.net>. Acesso em: 23 jul. 2012.

CHAMBERLAIN, Lis. Creativity and literacy. In: WILSON, Anthony (Org.). Creativity in primary education. Exeter: Learning Matters, 2005. p. 68-76.

COSTA, Marina Teixeira Mendes de Souza; SILVA, Daniele Nunes Henrique; SOUZA, Flavia Faissal de. Corpo, atividades criadoras e letramento. São Paulo: Summus, 2013.

FREIRE, Paulo. A importância do ato de ler: em três artigos que se completam. 51. ed. São Paulo: Cortez, 2011.

GONZÁLEZ REY, Fernando. A configuração subjetiva dos processos psíquicos: avançando na compreensão da aprendizagem como produção subjetiva. In: MITIJÁNS MARTÍNEZ, Albertina; SCOZ, Beatriz Judith Lima; CASTANHO, Marisa Irene Siqueira (Orgs.). Ensino e aprendizagem: a subjetividade em foco. Brasília, DF: Liber, 2012. p. 21-42.

GONZÁLEZ REY, Fernando. El pensamiento de Vigotsky: contradicciones, desdoblamientos y desarrollo. México: Trilhas, 2011 . GONZÁLEZ REY, Fernando. Epistemología cualitativa y subjetividad. São Paulo: Educ, 1997.

GONZÁLEZ REY, Fernando. 0 sujeito que aprende: desafios do desenvolvimento do tema da aprendizagem na psicologia e na prática pedagógica. In: TACCA, Maria Carmen (Org.). Aprendizagem e trabalho pedagógico. 2. ed. Campinas: Alínea, 2008. p. 29-44.

GONZÁLEZ REY, Fernando. Os aspectos subjetivos no desenvolvimento de crianças com necessidades especiais: além dos limites concretos do defeito. In: MITJÁNS MARTíNEZ, Albertina; TACCA, Maria Carmen Villela Rosa (Orgs.). Possibilidades de aprendizagem: ações pedagógicas para alunos com dificuldade e deficiência. Campinas: Alínea, 2011c. p. 47-70.

GONZÁLEZ REY, Fernando. Pesquisa qualitativa e subjetividade: os processos de construção da informação. São Paulo: Pioneira Thomson Learning, 2005.

GONZÁLEZ REY, Fernando. Questões teóricas e metodológicas nas pesquisas sobre a aprendizagem: a aprendizagem no nível superior. In: MITJÁNS MARTíNEZ, Albertina; TACCA, Maria Carmen (Orgs.). A complexidade da aprendizagem: destaque ao ensino superior. Campinas: Alínea, 2009. p. 119-148.

GONZÁLEZ REY, Fernando. Subjetividade e saúde: superando a clínica da patologia. São Paulo: Cortez, 2011b.

GONZÁLEZ REY, Fernando. Sujeito e subjetividade: uma aproximação histórico-cultural. São Paulo: Pioneira Thomson Learning, 2003.

GONZÁLEZ REY, Fernando; MITJÁNS MARTíNEZ, Albertina. La personalidad su educación y desarrollo. Habana: Pueblo y Educación, 1989.

HUIZINGA, Johan. Homo ludens: o jogo como elemento da cultura. 7. ed. São Paulo: Perspectiva, 1999.

KISHIMOTO, Tizuko Morchida et al. Jogo e letramento: crianças de 6 anos no ensino fundamental. Educação e Pesquisa, v. 37, n. 1, p. 191-210, jan./abr. 2011. Disponível em: <http://www.scielo.br/pdf/ep/v37n1/v37n1a12.pdf>. Acesso em: 07 jan. 2014.

LEITE, Sergio Antonio da Silva. A afetividade no processo de constituição do leitor. Atos de Pesquisa em Educação, Blumenau, v. 6, n. 1, p. 25-52, jan./abr. 2011.

MITJÁNS MARTÍNEZ, Albertina. Aprendizagem criativa: desafios para a prática pedagógica. In: NUNES, Cláudio Pinto (Org.). Didática e formação de professores. ljuí: Unijuí, 2012b. p. 93-124. 
MITJÁNS MARTÍNEZ, Albertina. Aprendizagem criativa: uma aprendizagem diferente. In: MITIJÁNS MARTÍNEZ, Albertina; SCOZ, Beatriz Judith Lima; CASTANHO, Marisa Irene Siqueira (Orgs.). Ensino e aprendizagem: a subjetividade em foco. Brasília, DF: Liber, 2012a. p. 85-109.

MITJÁNS MARTíNEZ, Albertina. Criatividade no trabalho pedagógico e criatividade na aprendizagem: uma relação necessária? In: TACCA, Maria Carmen Villela Rosa (Org.). Aprendizagem e trabalho pedagógico. Campinas: Alínea, 2008. p. 69-94.

MITJÁNS MARTÍNEZ, Albertina. Criatividade, personalidade e educação. 3. ed. Campinas: Papirus, 1997.

MITJÁNS MARTÍNEZ, Albertina. 0 outro e sua significação para criatividade: implicações educacionais. In: SIMÃo, Lívia Mathias; MITJÁNS MARTíNEZ, Albertina. (Orgs.). 0 outro no desenvolvimento humano: diálogos para a pesquisa e a prática profissional em psicologia. São Paulo: Thomson, 2004. p. 77-99.

MITJÁNS MARTÍNEZ, Albertina. Pensar, crear y transformar: desafíos para la educación. In: SIMPÓSIO MULTIDISCIPLINAR PENSAR CRIAR E TRANSFORMAR, 1., São Paulo, Universidade São Marcos, 2000. Anais... São Paulo: Unimarco, 2000.

MITJÁNS MARTíNEZ, Albertina. Processos de aprendizagem na pós-graduação: um estudo exploratório. In: MITJÁNS MARTíNEZ, Albertina; TACCA, Maria Carmen Villela Rosa. (Orgs.). A complexidade da aprendizagem: destaque ao ensino superior. Campinas: Alínea, 2009b. p. 213-262.

MITJÁNS MARTÍNEZ, Albertina. Vygotsky e a criatividade: novas leituras, novos desdobramentos. In: GIGLIO, Zula; WECHSLER, Solange Muglia; BRAGOTTO, Denise (Orgs.). Da criatividade à inovação. Campinas: Papirus, 2009a. p. 11-38.

MITJÁNS MARTíNEZ, Albertina; GONZÁLEZ REY, Fernando. 0 subjetivo e o operacional na aprendizagem escolar: pesquisas e reflexões. In: MITIJÁNS MARTÍNEZ, Albertina; SCOZ, Beatriz Judith Lima; CASTANHO, Marisa Irene Siqueira (Orgs.). Ensino e aprendizagem: a subjetividade em foco. Brasília, DF: Liber, 2012. p. 59-84.

MUNIZ, Luciana Soares; MITJÁNS MARTÍNEZ, Albertina. A aprendizagem da leitura e da escrita: análise da produção científica. Atos de Pesquisa em Educação - PPGE/ME, v. 8, n. 2, p. 778-809, maio/ago. 2013. Disponível em: <http://proxy.furb.br/ojs/ index.php/atosdepesquisa/article/view/3273>. Acesso em: 07 jan. 2014.

SMOLKA, Ana Luiza Bustamante. A criança na fase inicial da escrita: a alfabetização como processo discursivo. 13. ed. São Paulo: Cortez, 2008.

VIGOTSKI, Lev Semenovitch. Imaginação e criação na infância. São Paulo: Ática, 2009.

Recebido em: 11.04.2014.

Aprovado em: 12.08.2014.

Luciana Soares Muniz possui graduação em pedagogia pela Universidade Federal de Uberlândia, mestrado em educação pela Universidade Federal de Uberlândia e é doutoranda pela Universidade de Brasília. É professora da escola de educação básica da Universidade Federal de Uberlândia.

Albertina Mitjáns Martínez é doutora em ciências psicológicas pela Universidade de La Havana, pós-doutorada pela Universidade Autônoma de Madri, professora associada da Universidade de Brasília e professora colaboradora da Universidade de Buenos Aires. 